Check for updates

Cite this: RSC Adv., 2017, 7, 20611

\title{
Preparation and structural-optical characterization of dip-coated nanostructured Co-doped ZnO dilute magnetic oxide thin films
}

\author{
L. R. Valério, ${ }^{a}$ N. C. Mamani, ${ }^{\text {ab }}$ A. O. de Zevallos, ${ }^{\text {ab }}$ A. Mesquita, ${ }^{c}$ M. I. B. Bernardi, ${ }^{d}$ \\ A. C. Doriguetto ${ }^{b}$ and H. B. de Carvalho (D) *a
}

\begin{abstract}
$\mathrm{ZnO}$-based materials are one of the most studied systems. Their applicability spans over several research areas and industries, like optoelectronics, catalysis and spintronics. Here we demonstrate the feasibility to prepare Co-doped $\mathrm{ZnO}$ thin films $\left(\mathrm{Zn}_{1-x} \mathrm{Co}_{x} \mathrm{O}\right.$, with $x=0 ; 0.01 ; 0.03$ and 0.05$)$ deposited by the dip-coating technique, a very simple and a low-cost process. We focus the structural and the optical characterization in the context of dilute magnetic materials. Detailed analyses were carried out to investigate alternative sources of ferromagnetism, such as secondary phases and nanocrystals embedded in the nanostructured thin films. Conjugating different techniques, we confirmed the $\mathrm{Zn}$ replacement by $\mathrm{Co}$ ions in the $\mathrm{ZnO}$ wurtzite structure with no secondary phases up to $x=0.05$. It was further observed that the major structural defects in the films are oxygen vacancies $\left(V_{O}\right)$ and zinc interstices $\left(Z n_{i}\right)$, and that the relative densities of these defects increase with the increase in Co concentration, which promotes the studied thin films to candidates to present room temperature ferromagnetism.
\end{abstract}

Received 27th January 2017

Accepted 16th March 2017

DOI: $10.1039 / c 7 r a 01200 d$

rsc.li/rsc-advances ferromagnetic, nevertheless, the Curie temperature $\left(T_{\mathrm{C}}\right)$ for these materials is still far below room temperature, not exceeding $200 \mathrm{~K} .{ }^{8,9}$ According to Dietl et al., ${ }^{10}$ Mn-doped ZnO and GaN, wide band gap semiconductors, theoretically would present $T_{\mathrm{C}}$ above room temperature. However, the obtained results, especially for the TM-doped oxides such as $\mathrm{ZnO}, \mathrm{TiO}_{2}$, $\mathrm{CeO}_{2}, \mathrm{SnO}_{2}$, etc., ${ }^{11-14}$ the dilute magnetic oxides (DMOs), regarding the origin of ferromagnetism, in retrospect, are now very controversial and inconclusive. The complete comprehension of the magnetic properties of these systems were hindered by several and different problems, among them we cite: the contamination by magnetic elements, ${ }^{15}$ measurement errors ${ }^{16}$ and the presence of not detected ferromagnetic segregated secondary phases. ${ }^{17,18}$ Today there is a consensus that the TMdoping is not a sufficient condition to achieve the room temperature ferromagnetism (RTFM), ${ }^{\mathbf{1 9 , 2 0}}$ and that point defects in the structure of such materials play an important role to reach the desired magnetic properties. ${ }^{21-25}$ Therefore, before to study the magnetic properties of these systems, it is preponderant to perform a carefully and detailed structural characterization in order to exclude the presence of any extrinsic magnetic component and to get some insight about the structural defects in the studied materials. From the theoretical point of view, the main models proposed to describe the origin and properties of ferromagnetism suppose that electrons, introduced by donor defects into the conduction band ${ }^{26}$ or forming bound magnetic polarons (BMP), ${ }^{27}$ mediate ferromagnetic couplings between TM ions in the oxide matrix. Another important model, attempting to explain the observed RTFM in
Instituto de Ciências Exatas, Universidade Federal de Alfenas - UNI 37133-840 Alfenas, MG, Brazil. E-mail: bonette@unifal-mg.edu.br

${ }^{b}$ Instituto de Química, Universidade Federal de Alfenas - UNIFAL-MG, 37130-001 Alfenas, $M G$, Brazil

${ }^{c}$ Departamento de Física, Instituto de Geociências e Ciências Exatas, Universidade Estadual Paulista - UNESP, 13500-900 Rio Claro, SP, Brazil

${ }^{d}$ Instituto de Física de São Carlos, Universidade de São Paulo - USP, 13560-970 São Carlos, SP, Brazil 
undoped systems, ${ }^{28}$ assigns the ferromagnetic response to spins of electrons residing on point or extended defects, the called $\mathrm{d}^{0}$ ferromagnetism. ${ }^{29}$

The aim of this present work is to prepare and present the structural and optical characterization of Co-doped $\mathrm{ZnO}$ thin films $\left(\mathrm{Zn}_{1-x} \mathrm{Co}_{x} \mathrm{O}\right)$ at concentrations of $x=0 ; 0.01 ; 0.03$ and 0.05 , deposited by the dip-coating technique. In spite of the potential application of the ZnO-based materials in the development of spintronic devices, they are one of the really multifunctional materials, been also highly interesting as in solar cells, ${ }^{30}$ gas sensing, ${ }^{31}$ transparent conductive oxides (TCOs) ${ }^{32}$ and also in catalysis, ${ }^{33}$ just to cite few. Among the TM elements used to dope $\mathrm{ZnO}$, Co deserves special attention, since it has one of the highest magnetic moments $\left(4.8 \mu_{\mathrm{B}}\right)$ and a positive magnetic exchange coupling constant in the metallic phase. Here, the global rout process of the thin films consists in preparing coating solutions from the Pechini method. ${ }^{34}$ Precursor films, deposited by dip-coating are then heat treated to eliminated organic materials and to synthesize the inorganic phase. The polymeric precursor method presents many advantages, such as the possibility to work in aqueous solution and a high stoichiometric control. Moreover, it is a low temperature process and a cost-effective method involving inexpensive precursors and unsophisticated apparatus. We performed a detailed structural characterization by conjugating several different techniques, in order to exclude the presence of any contamination or segregated secondary phases that could lead to any extrinsic and undesired magnetic component. The optical characterization was employed to get fundamental insights concerning the nature and the relative density of defects in the prepared thin films.

\section{Experimental}

The $\mathrm{Zn}_{1-x} \mathrm{Co}_{x} \mathrm{O}$ thin films were deposited on glass substrates by the dip-coating method with Co nominal concentrations of $x=$ 0 (undoped $\mathrm{ZnO}) ; 0.01\left(\mathrm{Zn}_{0.99} \mathrm{Co}_{0.01} \mathrm{O}\right) ; 0.03\left(\mathrm{Zn}_{0.97} \mathrm{Co}_{0.03} \mathrm{O}\right)$ and $0.05\left(\mathrm{Zn}_{0.95} \mathrm{Co}_{0.05} \mathrm{O}\right)$. Flowchart in Fig. 1 illustrates the procedure employed in the preparation of the thin films. The dipcoating process consists of an equipment, provided with a stepper motor that, when moving the lever on which the substrate is fixed, allows to immerse and remove it from a coating resin prepared by the Pechini method. ${ }^{34}$ Zinc nitrate hexahydrate, $\mathrm{Zn}\left(\mathrm{NO}_{3}\right)_{2} \cdot 6 \mathrm{H}_{2} \mathrm{O}$ (Sigma-Aldrich, >99\%), and cobalt(II) nitrate hexahydrate, $\mathrm{Co}\left(\mathrm{NO}_{3}\right)_{2} \cdot 6 \mathrm{H}_{2} \mathrm{O}$ (Sigma-Aldrich, $\geq 98 \%$ ), were the metal sources used in stoichiometric amounts in the synthesis of the precursor coating resin. In the first step, the nitrates were dissolved in an aqueous citric acid solution at $60^{\circ} \mathrm{C}$ under constant stirring for approximately $1 \mathrm{~h}$. After achieve a completely homogeneous solution, ethylene glycol was added to promote an organic ester formation. Polymerization, promoted by heating the mixture up to $120{ }^{\circ} \mathrm{C}$, results in a homogeneous resin in which metal ions are uniformly distributed throughout the organic matrix. The citric $\mathrm{acid} / \mathrm{metal}$ and citric acid/ethylene glycol mass ratios were $4: 1$ and $60: 40$, respectively. The viscosity was then adjusted to 15 $\mathrm{cP}$ by adding a controlled amount of water. Prior to coating, the

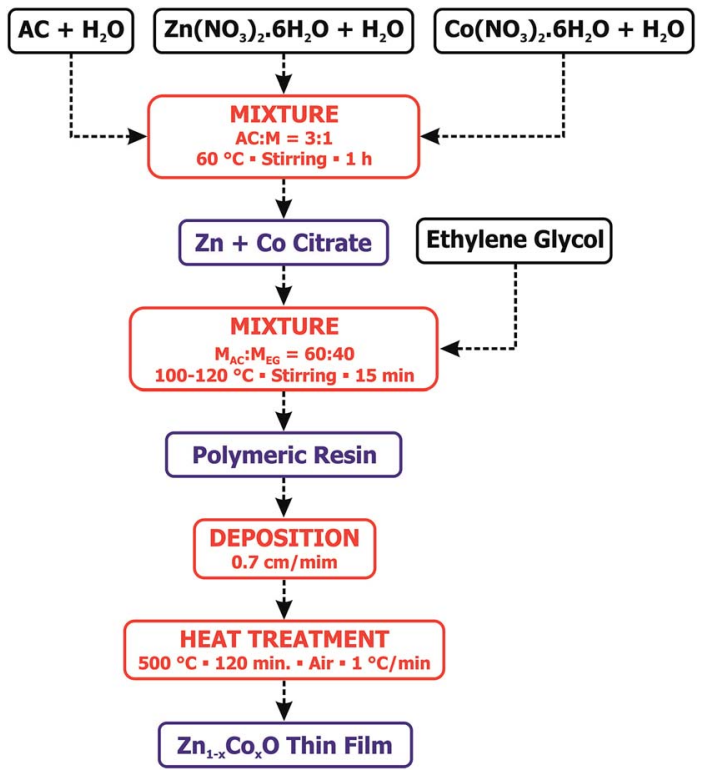

Fig. 1 Flowchart of the preparation of the $\mathrm{Zn}_{1-x} \mathrm{Co}_{x} \mathrm{O}$ thin films using the polymeric precursor method.

substrates were cleaned in a sulfochromic solution followed by washing several times in de-ionized water and drying in hot air. The dip-coating was conducting by immersing the clean substrates in the polymeric resin followed by controlled withdrawal at the speed of $0.7 \mathrm{~cm} \mathrm{~min}^{-1}$. After deposition, the substrates were dried on a hot plate $\left(\sim 150^{\circ} \mathrm{C}\right)$. Finally, the glass substrates with the deposited films were subjected to a heat treatment at $500{ }^{\circ} \mathrm{C} / 2 \mathrm{~h}$ in air, with heating rate of $1^{\circ} \mathrm{C} \mathrm{min}^{-1}$, in order to remove the organic materials and to promote the crystallization of the thin film. The average thicknesses of the films were measured by using a Talystep Taylor-Hobson profiler. The obtained value for all the thin films were $400 \pm$ $10 \mathrm{~nm}$.

The structural characterization was investigated by powder X-ray diffraction (PXRD) using a Rigaku Ultima IV diffractometer, geometry $\theta-2 \theta$, Cu-K $\alpha(\lambda=1.5418 \AA)$ radiation and a $\operatorname{LiF}(100)$ monochromator. The PXRD data were measured in a step-scan mode at room temperature, in a range of $2 \theta=10-$ $90^{\circ}$ with a rate of $0.02^{\circ} / 5 \mathrm{~s}$. The structure morphology and the elemental composition were characterized by scanning electron microscopy (SEM) and energy dispersive X-ray spectrometry (EDS) by means of a FEI Inspect F50, equipped with an Oxford EDS detector, model X-MAX 80. The optical properties were evaluated via optical transmittance (UV-Vis) and photoluminescence (PL) techniques. The UV-Vis measurements were performed on a Carry-17 spectrometer operating in a region from 300 to $900 \mathrm{~nm}$. The PL measurements were performed at a $5 \mathrm{~K}$ temperature with a Kimmon Koha $\mathrm{He}-\mathrm{Cd}$ laser at $325 \mathrm{~nm}$, as the source of excitation. Finally, the local structure of the Co dopants into the $\mathrm{ZnO}$ matrix and their oxidation state were determined by X-ray absorption techniques (X-ray absorption near-edge structure - XANES and extended X-ray absorption fine structure - EXAFS). The X-ray absorption measurements were performed at the Co K-edge in transmission mode using 
a $\mathrm{Si}(111)$ channel-cut monochromator at the XAFS2 beamline from the Brazilian Synchrotron Light Laboratory (LNLS), Campinas, Brazil. The extraction, normalization and fitting of the EXAFS spectra were performed using the Multiplatform Applications for XAFS (MAX) software package and theoretical spectra were obtained using the FEFF9 code..$^{35,36}$

\section{Results and discussions}

Fig. 2 shows the diffractograms obtained for the prepared thin films. For all samples, the diffraction peaks correspond to those of the ZnO wurtzite structure (ICDD crystal chart no. 36-1451). The results show that, within the technique limits of detection, there are no secondary phases present in the thin films, indicating that the Co ions are incorporated into the $\mathrm{ZnO}$ matrix. The observed wide curve superimposed on the $\mathrm{ZnO}$ wurtzite diffraction peaks at lower angles $\left(2 \theta\right.$ from $15^{\circ}$ to $\left.40^{\circ}\right)$ is associated to the diffraction of the amorphous material of the glass substrate.

The study of the thin film morphology and chemical composition was carried out using both scanning electron microscopy (SEM) and energy dispersive X-ray spectroscopy (EDS) techniques. Fig. 3 shows the data obtained for the undoped $\mathrm{ZnO}$ sample, a representative image of the thin film

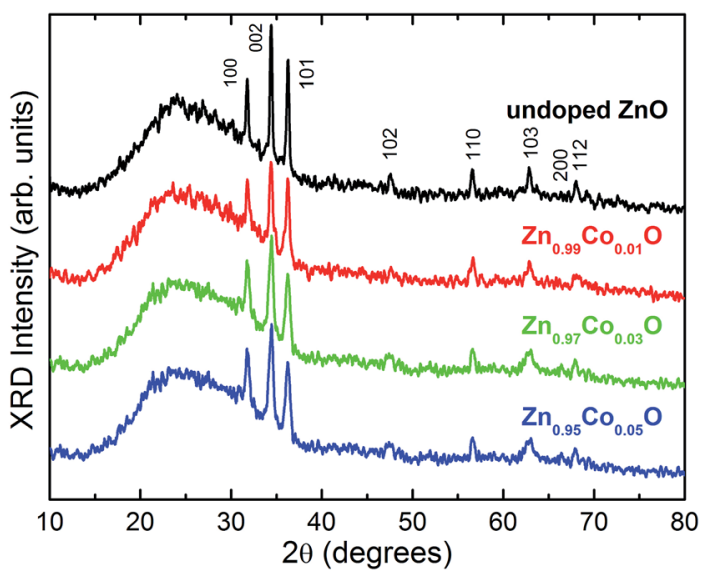

Fig. 2 Powder X-ray diffractograms $(\mathrm{Cu}-\mathrm{K} \alpha)$ obtained for the $\mathrm{Zn}_{1-x^{-}}$ $\mathrm{Co}_{x} \mathrm{O}$ thin films. The crystalline planes for each diffraction peak, given in the Miller indices (ICDD PDF no. 36-1451), are also shown. surface (Fig. 3(a)) with the respective EDS spectrum (Fig. 3(b)) and the obtained histogram used for the statistical analyses of the grain diameter distribution (Fig. 3(c)). The obtained statistical data for the other samples are similar to those shown in Fig. 3 and are summarized in Table 1.

We observed that thin films have a nanometric granular structure (inset of Fig. 3(a)). Scans were performed on several areas of the thin films in order to search for potential segregated secondary phases and EDS analyses were carried out on the suspect grains. The presence of these phases was not detected at any point, strongly suggesting that Co ions in the studied thin films is in substitutional character to the $\mathrm{Zn}^{2+}$ ions into the $\mathrm{ZnO}$ wurtzite matrix. The EDS analyses also give the Co concentrations in semi-quantitative values. The measured average effective Co concentrations $\left(x_{\mathrm{E}}\right)$ listed in Table 1 are in good agreement with the nominal stoichiometry of the thin films. The statistical analyses were conducted by measuring the grain sizes in different images with the aid of Image Pro 4 software. The obtained histograms were then fit by a log-normal function, which gives the geometric main grain diameter $(d)$ and the geometric standard deviation $\left(\sigma_{\mathrm{g}}\right)$ of the distributions. The obtained results are also listed in Table 1. We observe that the grain median diameters are of order of $50 \mathrm{~nm}$ and that the geometric standard deviation for all the thin films are lower than 1.25. Considering that a grain size distribution is said to be monodispersed if $\sigma_{\mathrm{g}} \leq 1.25,{ }^{37}$ we can state that the grain sizes of our thin films are quite homogeneous.

Now, we proceed to the optical characterization results. Fig. 4(a) shows the transmittance spectra for the thin films, in the range from 350 to $850 \mathrm{~nm}$ measured at room temperature. The observed spectra were very similar to those found in literature, ${ }^{38}$ with the $\mathrm{ZnO}$ absorption edge in the range of $380 \mathrm{~nm}$

Table 1 Particle size distribution analyses. Effective Co concentration $\left(x_{\mathrm{E}}\right)$, median diameter $(d)$, geometric standard deviation $\left(\sigma_{\mathrm{g}}\right)$ and the total number of counted particles $(N)$

\begin{tabular}{lllll}
\hline Sample & $x_{\mathrm{E}}$ & $d(\mathrm{~nm})$ & $\sigma_{\mathrm{g}}$ & $N$ \\
\hline Undoped $\mathrm{ZnO}$ & - & $56(1)$ & $1.25(2)$ & 168 \\
$\mathrm{Zn}_{0.99} \mathrm{Co}_{0.01} \mathrm{O}$ & $0.010(1)$ & $45.9(7)$ & $1.21(2)$ & 76 \\
$\mathrm{Zn}_{0.97} \mathrm{Co}_{0.03} \mathrm{O}$ & $0.030(1)$ & $56.2(9)$ & $1.18(1)$ & 111 \\
$\mathrm{Zn}_{0.95} \mathrm{Co}_{0.05} \mathrm{O}$ & $0.048(1)$ & $48(1)$ & $1.17(1)$ & 281
\end{tabular}
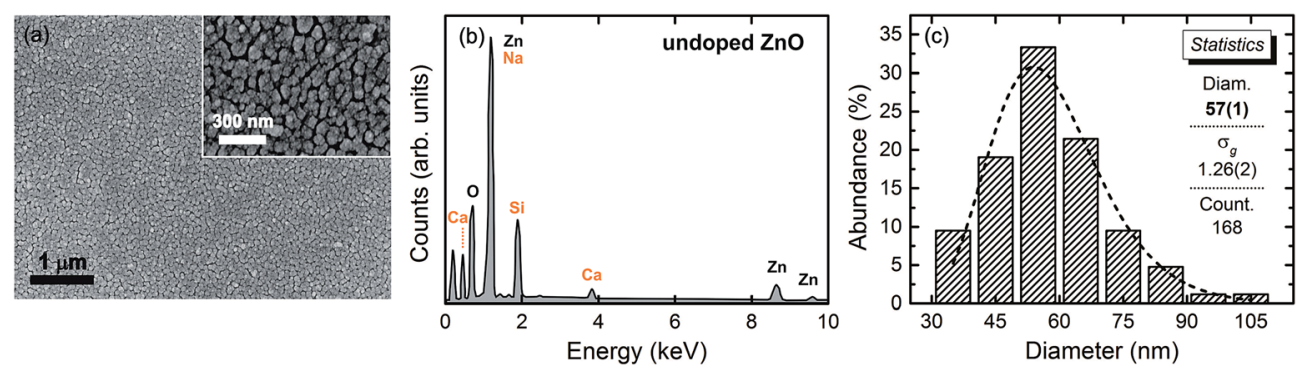

Fig. 3 (a) Representative micrograph obtained by SEM for the undoped ZnO thin film; (b) respective EDS spectrum of the visualized area in (a), the elements corresponding to the glass substrate are $\mathrm{Ca}, \mathrm{Na}$ and $\mathrm{Si}$. (c) Particle size distribution histogram for the undoped $\mathrm{ZnO}$ sample. The dashed line in (c) corresponds to a log-normal fit. 

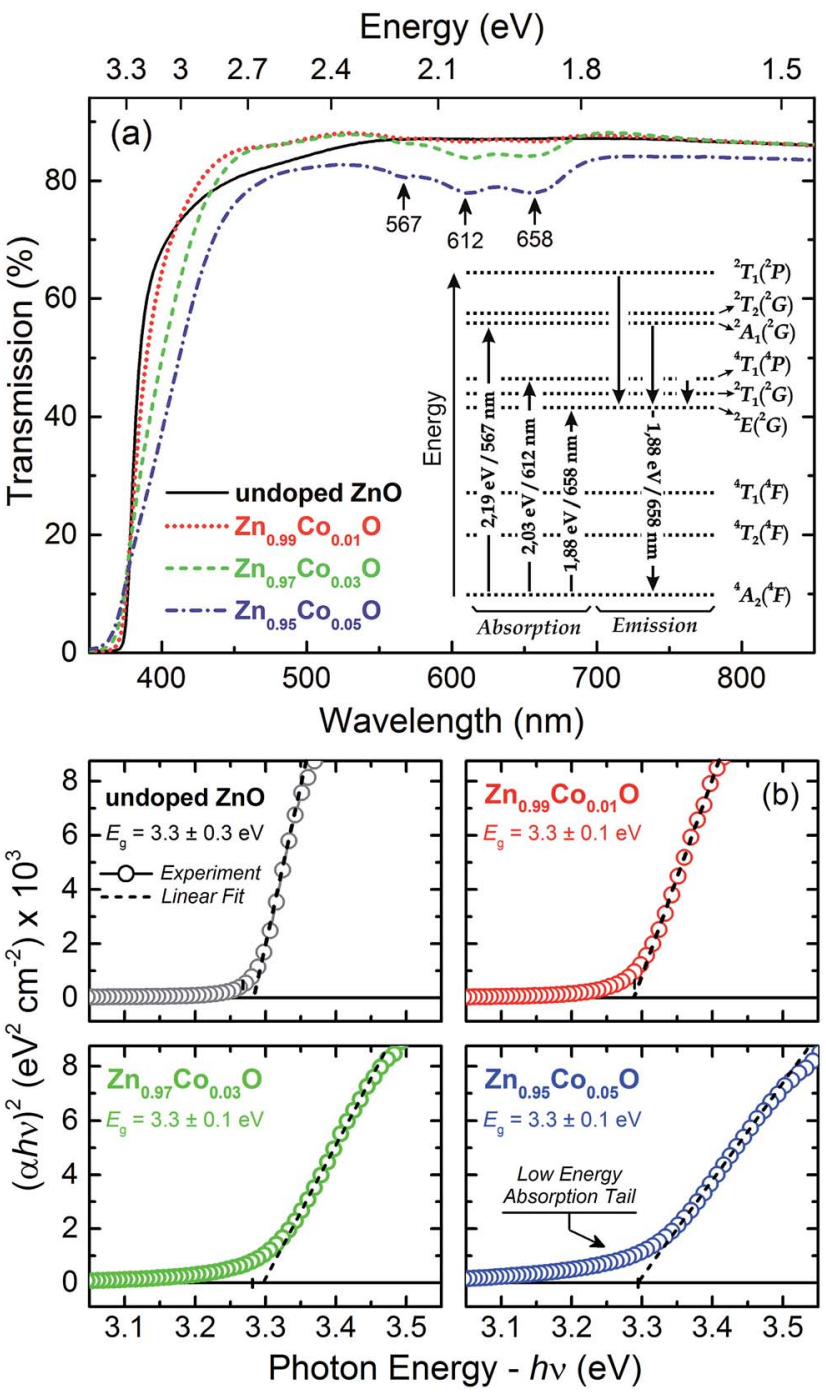

Fig. 4 (a) Transmission spectra (UV-Vis) in the range from 350 to $850 \mathrm{~nm}$ for the $\mathrm{Zn}_{1-x} \mathrm{Co}_{x} \mathrm{O}$ thin films. Inset in (a) is the energy diagram for $\mathrm{Co}^{2+}$ ions at a tetrahedral site (out off-scale). (b) $(\alpha h \nu)^{2}$ curves as a function of the energy of the incident photon near the band gap region of the thin films. The intercept of the line segments (dashed lines), obtained from the linear fitting of the absorption edges, with the energy axis gives the direct value of the energy band gap $\left(E_{\mathrm{g}}\right)$.

and absorption bands at 567, 612 and $658 \mathrm{~nm}$ associated with $\mathrm{Co}^{2+}$ ions at the $3 \mathrm{~d}^{7}$ tetrahedral coordination, with the ${ }^{4} \mathrm{~F}$ state corresponding to the lowest energy state, as well as the ${ }^{4} \mathrm{P},{ }^{2} \mathrm{G}$, ${ }^{2} \mathrm{P},{ }^{2} \mathrm{H}$ and ${ }^{2} \mathrm{D}$ states corresponding to the excited states. ${ }^{39}$ Once in a tetrahedral site, the ${ }^{4} \mathrm{~F}$ state splits into ${ }^{4} \mathrm{~A}_{2}\left({ }^{4} \mathrm{~F}\right),{ }^{4} \mathrm{~T}_{2}\left({ }^{4} \mathrm{~F}\right)$ and ${ }^{4} \mathrm{~T}_{1}\left({ }^{4} \mathrm{~F}\right)$ due to the crystalline field, here, ${ }^{4} \mathrm{~A}_{2}\left({ }^{4} \mathrm{~F}\right)$ state became the fundamental one. Likewise, the ${ }^{2} \mathrm{G}$ state splits into ${ }^{2} \mathrm{~A}_{1}\left({ }^{2} \mathrm{G}\right)$, ${ }^{2} \mathrm{E}\left({ }^{2} \mathrm{G}\right),{ }^{2} \mathrm{~T}_{1}\left({ }^{2} \mathrm{G}\right)$ and ${ }^{2} \mathrm{~T}_{2}\left({ }^{2} \mathrm{G}\right)$. However, the excited states ${ }^{4} \mathrm{P}$ and ${ }^{2} \mathrm{P}$ do not split, but are converted into the ${ }^{4} \mathrm{~T}_{1}\left({ }^{4} \mathrm{P}\right)$ and ${ }^{2} \mathrm{~T}_{1}\left({ }^{2} \mathrm{P}\right)$ states, respectively. The inset in Fig. 4(a) shows the energy diagram for $\mathrm{Co}^{2+}$ ion in a tetrahedral site. In this context, the absorptions observed at 567, 612 and $658 \mathrm{~nm}$ is attributed to the transitions ${ }^{4} \mathrm{~A}_{2}(\mathrm{~F}) \rightarrow{ }^{2} \mathrm{~A}_{1}(\mathrm{G}),{ }^{4} \mathrm{~A}_{2}(\mathrm{~F}) \rightarrow{ }^{4} \mathrm{~T}_{1}(\mathrm{P})$ and ${ }^{4} \mathrm{~A}_{2}(\mathrm{~F}) \rightarrow$ ${ }^{2} \mathrm{E}(\mathrm{G}){ }^{40}$ Therefore, the observation of these transitions for our doped thin films is an indication that the Co ions in $\mathrm{ZnO}$ matrix have a +2 oxidation state and are located in a tetrahedral site. In the wurtzite structure of the $\mathrm{ZnO}$ matrix, the tetrahedral sites correspond to those of the $\mathrm{Zn}^{2+}$ ions, thus we can state that the Co in our films is in substitutional character to $\mathrm{Zn}$ in the $\mathrm{ZnO}$ wurtzite structure of the thin films.

The calculation of the effective optical band gap $\left(E_{\mathrm{g}}\right)$ of the thin films were performed by the Tauc method. ${ }^{41}$ Fig. 4(b) shows the $(\alpha h \nu)^{2}$ graphs as a function of the excitation energy, as well as the $E_{\mathrm{g}}$ values obtained by the linear fitting the edge of the $(\alpha h \nu)^{2}$ curves for the studied thin films. We observed that there is no significant variation of $E_{\mathrm{g}}$ as a function of Co doping, remaining with an average value of $3.30 \mathrm{eV}$. This result indicates that the doping does not significantly introduce structural distortions in the $\mathrm{ZnO}$ matrix. In the $\mathrm{ZnO}$ wurtzite structure, the $\mathrm{Zn}^{2+}$ ion in a tetrahedral coordination has a crystal radius of $0.74 \AA$; whereas, the $\mathrm{Co}^{2+}$ ion in the same structure, in a tetrahedral coordination, must have a crystalline radius of $0.72 \AA$, very little different from the $\mathrm{Zn}^{2+}$ crystal radius. ${ }^{42}$ Given the small difference between the crystal radii of these two elements, it is would be expected that the Co doping of the $\mathrm{ZnO}$ matrix would does not introduce significant distortions, considering that the $\mathrm{Co}^{2+}$ ions replaces the $\mathrm{Zn}^{2+}$ ions by taking over its position in the $\mathrm{ZnO}$ structure. In fact, this was what we observed, so that the obtained result also indicates the substitutional character of Co doping in our $\mathrm{Zn}_{1-x} \mathrm{Co}_{x} \mathrm{O}$ thin films.

Another important feature observed in the Tauc plots is the evident decrease of the slope of the edge and a formation of a low energy absorption tail as increasing the co content in the thin films. In studies of amorphous solids, the slope of the Tauc plot has been used as a measure of the disorder effects in the band edge. The disorder effects become larger, than the slope becomes gentler. In fact, disorder generates defects, and these, in turn, remove states from the bands and generate band tails of localized states. ${ }^{\mathbf{4 3 , 4 4}}$ The appearance of a low energy absorption tail with the Co-doping into the $\mathrm{ZnO}$ matrix has been reported previously by us and other authors, ${ }^{25,44}$ and was attributed to the formation of an impurity band near to the conduction band edge due to the overlapping of states introduced by the Co-doping. ${ }^{45}$ These assumptions were further confirmed by the PL analyses.

Point defects directly affect the band structure of a material, playing a very important role in the optical, electrical and magnetic properties of TM-doped oxide systems. However, the study of point defects in materials is a very hard task. One of the most important defect characterization techniques, once taking into account theoretical calculations of electronic structure, is the PL measurements. In this sense, we carried out PL measurements in our thin films, in order to obtain information about the electronic structure, and to identify the major defects present in the films, as well as their relative densities. Fig. 5(a) shows the spectra obtained for the $\mathrm{Zn}_{1-x} \mathrm{Co}_{x} \mathrm{O}$ thin films. The spectra can be divided into three distinct emissions: (i) an emission at approximately $3.35 \mathrm{eV}$, addressed to transition between states close to the $\mathrm{ZnO}$ conduction and valence band edges; this band is denominated as near band edge emission (NBE); (ii) a large emission extending from approximately $3.25 \mathrm{eV}$ to $1.6 \mathrm{eV}$, associated with structural defect transitions; and (iii) the $\mathrm{Co}^{2+}$ emission band at around $1.86 \mathrm{eV}$. 


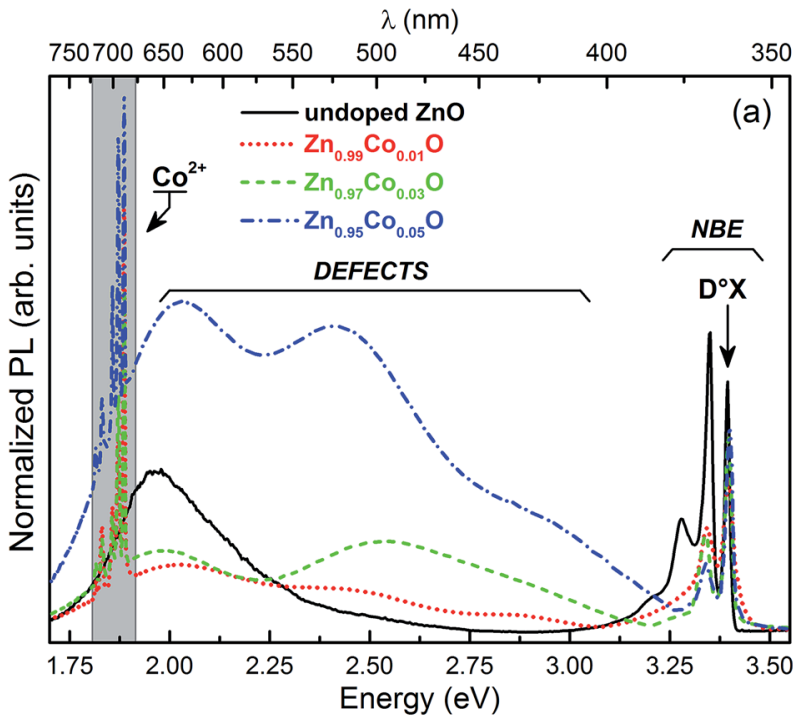

$\lambda(\mathrm{nm})$

$\lambda(\mathrm{nm})$

$381378375372369366363360 \quad 685680675670665660655650$

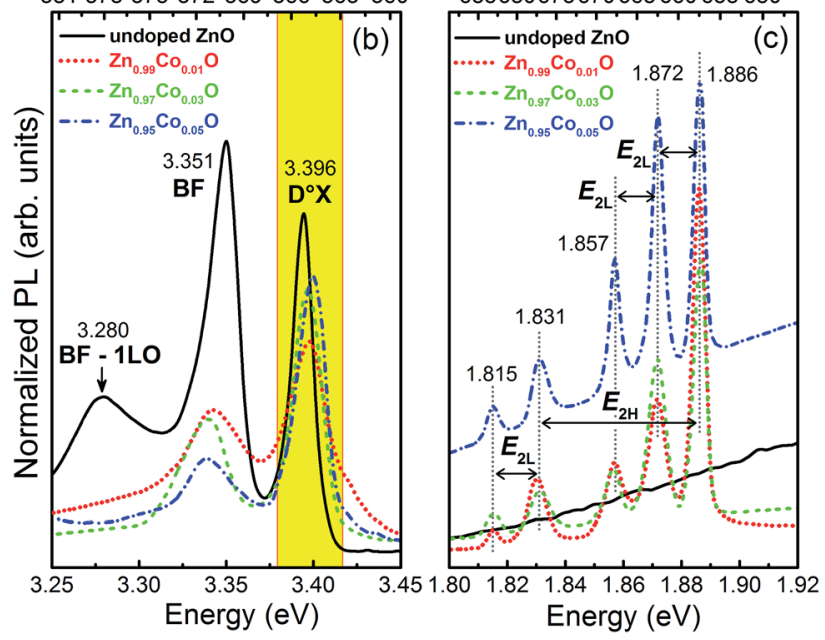

Fig. 5 (a) Photoluminescence spectra obtained at a $5 \mathrm{~K}$ for the $\mathrm{Zn}_{1-x} \mathrm{Co}_{x} \mathrm{O}$ thin films. The spectra are normalized by the integrated area of the denominated $D^{\circ} X$ emission band in the NBE region. Details of spectra in the NBE region (b) and in the $\mathrm{Co}^{2+}$ emission region (c).

Fig. 5(b) shows the NBE emission in detail. We can observe three different emission bands in this region. The band at $3.40 \mathrm{eV}$ is associated with excitons bound to neutral donors defect state $\left(\mathrm{D}^{\circ} \mathrm{X}\right)$. The band centered at $3.35 \mathrm{eV}$ is associated with recombination of electrons bound to donor defects with free holes in the valence band $(\mathrm{BF})$; finally, the emission at $3.28 \mathrm{eV}$ is a longitudinal optical (LO) phonon replica of the $\mathrm{BF}$ emission (BF-1LO), corresponding to $70 \mathrm{meV}$ below the $\mathrm{BF}$ energy. ${ }^{46}$ Fig. 5(c) shows the $\mathrm{Co}^{2+}$ emission region. The emission band at $1.886 \mathrm{eV}$ is associated with relaxations from excited states to ${ }^{2} \mathrm{E}\left({ }^{2} \mathrm{G}\right)$ state, followed by a transition from ${ }^{2} \mathrm{E}\left({ }^{2} \mathrm{G}\right)$ to the ${ }^{4} \mathrm{~A}_{2}\left({ }^{4} \mathrm{~F}\right)$ ground state of $\mathrm{Co}^{2+}$ in the $3 \mathrm{~d}^{7}$ configuration in a tetrahedral crystalline field formed by the $\mathrm{O}^{2-}$ ions in its neighborhood (inset in Fig. 4(a)). The energy difference between the bands at $1.886 \mathrm{eV}$ and $1.831 \mathrm{eV}$ is $0.055 \mathrm{eV}$, which exactly corresponds to the energy of the vibrational mode $E_{2 \mathrm{H}}(0.054 \mathrm{eV} /$ $\left.437 \mathrm{~cm}^{-1}\right)$, normally observed for both undoped and TM-doped
ZnO wurtzite structure. ${ }^{\mathbf{2 4 , 4 7 , 4 8}}$ The difference in energy among the $1.886 \mathrm{eV}, 1.872 \mathrm{eV}$ and $1.857 \mathrm{eV}$ bands, as well as the energy difference between the $1.831 \mathrm{eV}$ and $1.815 \mathrm{eV}$ bands, are $0.014 \mathrm{eV}, 0.015 \mathrm{eV}$ and $0.16 \mathrm{eV}$, respectively. These values, in turn, are in accordance with the energy for the vibrational mode $E_{2 \mathrm{~L}}\left(0.013 \mathrm{eV} / 105 \mathrm{~cm}^{-1}\right) .{ }^{49}$ The identification of these phonons in the PL spectra related to the $\mathrm{Co}^{2+}$ inner transitions is a clearly evidence that the Co ions in our thin films are, in fact, incorporated into the $\mathrm{ZnO}$ matrix.

Fig. 6 presents in more details the spectral region where it is observed the emission bands related to structural defects. The spectra were adjusted by Gaussians curves in order to identify and determine the relative contribution of each emission band. The observed spectra were composed of three emission bands centered on approximately $1.984 \mathrm{eV}$ (620 nm - red), $2.449 \mathrm{eV}$ (506 nm - green) and $2.895 \mathrm{eV}(428 \mathrm{~nm}$ - blue); except for the undoped $\mathrm{ZnO}$ thin film, for which we observed an additional band at $2.182 \mathrm{eV}$ (568 $\mathrm{nm}$ - green) but the band at $2.895 \mathrm{eV}$ is not observed. As mentioned before, indexing the observed bands to specific defects is a difficult task, and is still a very controversial issue, leading to intense debate in the academic community. We have decided to follow both experimental and theoretical representative ref. 50-52. Here, the band around $1.984 \mathrm{eV}$ is associated with oxygen vacancies $\left(\mathrm{V}_{\mathrm{O}}\right)$, whereas, the band at approximately $2.182 \mathrm{eV}$ is attributed to oxygen interstitial $\left(\mathrm{O}_{\mathrm{i}}\right)$. The band at approximately $2.449 \mathrm{eV}$, in turn, is related to transitions between acceptor levels and shallow donors, the

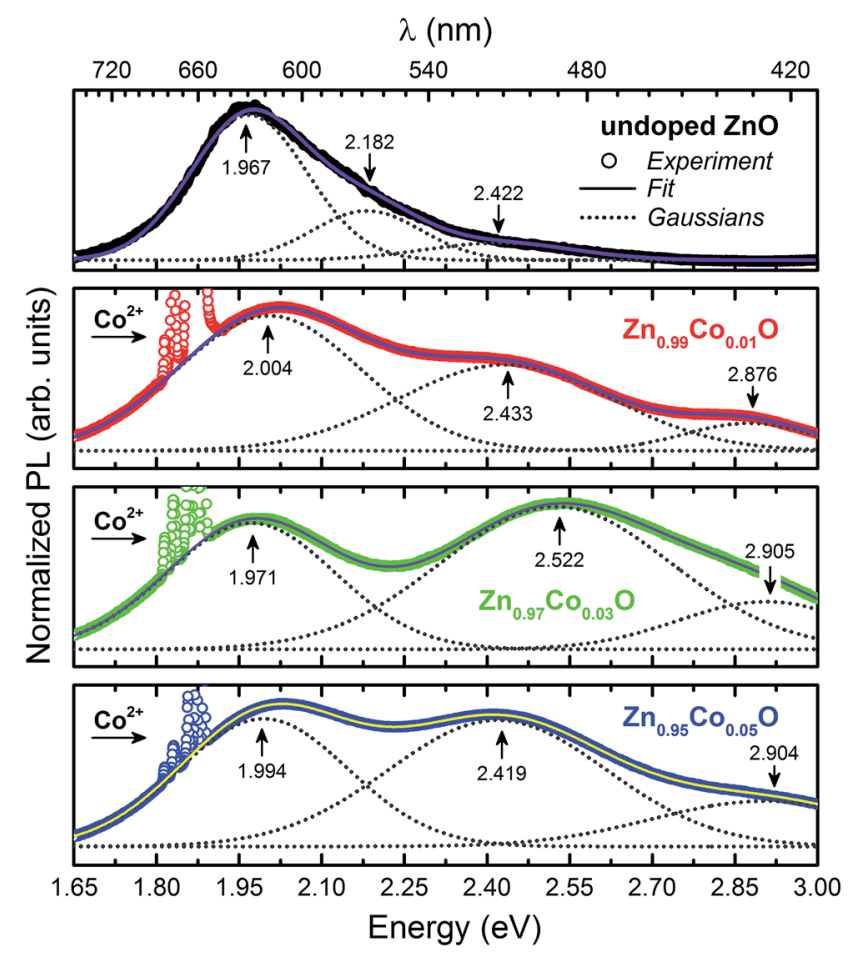

Fig. 6 Detail of the emission spectra of the $\mathrm{Zn}_{1-x} \mathrm{Co}_{x} \mathrm{O}$ thin films in the region associated with structural defects. The symbols correspond to the experimental data, whereas, the doted lines correspond to the Gaussian ones, used to adjust the emission spectrum for each thin film. The solid lines correspond to the obtained fitting. 
most promising candidates are interstitials zinc $\left(\mathrm{Zn}_{\mathrm{i}}\right)$ and zinc vacancies $\left(\mathrm{V}_{\mathrm{Zn}}\right)$. Finally, the band at $2.895 \mathrm{eV}$ can be associated directly with $\mathrm{Zn}_{\mathrm{i}}$. It is worthy to note that we would expect to observe an emission band also directly associated with the $\mathrm{V}_{\mathrm{Zn}}$ defects around $3 \mathrm{eV}$ and $3.1 \mathrm{eV}$, that is, close to the NBE region. Nevertheless, we did not explicitly observe this band (Fig. 5(a)), which means that if these defects existed in our thin films, at least they are in relative low concentrations.

The relative intensities of the emission bands can be directly correlated to the defect densities present in the thin films. Table 2 present the intensities (integrated areas) obtained after the Gaussian fit of the acquired spectra for the thin films. We observed that in a general way the defect bands intensities increases as the Co content increases, and that the structural defects mostly present in the $\mathrm{Zn}_{1-x} \mathrm{Co}_{x} \mathrm{O}$ thin films are $\mathrm{V}_{\mathrm{O}}$ and $\mathrm{Zn}_{\mathrm{i}}$. These data corroborate the observed behavior in the UV-Vis analyses where disorder related defects increases as a function of the Co concentration in the thin films. In particular, concerning the emission bands associated with defects at the $\mathrm{Zn}$ sites $\left(\mathrm{Zn}_{\mathrm{i}} \rightarrow \mathrm{V}_{\mathrm{Zn}}\right.$ and $\left.\mathrm{Zn}_{\mathrm{i}}\right)$, as we did not observe an emission band directly associated with $\mathrm{V}_{\mathrm{Zn}}$, we interpreted the increase of the intensities of these emissions with the Co-doping due to the increase in the $\mathrm{Zn}_{\mathrm{i}}$ concentration. This interpretation lead us to infer that the dynamics of the Co incorporation into the $\mathrm{ZnO}$ matrix starts by filling the empty $\mathrm{Zn}$ sites (decreasing of the $\mathrm{V}_{\mathrm{Zn}}$ ), and then, from a determinate point, pushing the $\mathrm{Zn}$ ions to interstitials sites (increasing of the $\mathrm{Zn}_{\mathrm{i}}$ ). Whereas, the bands associated to the defects at the oxygen site $\left(\mathrm{V}_{\mathrm{O}}\right.$ e $\left.\mathrm{O}_{\mathrm{i}}\right)$, which is very evident in the undoped $\mathrm{ZnO}$ thin film spectrum, did not present a correlation with the Co-doping. The $\mathrm{V}_{\mathrm{O}}$ emission band initially decreased with the doping $\left(\mathrm{Zn}_{0.99} \mathrm{Co}_{0.01} \mathrm{O}\right)$, but then it started increasing $\left(\mathrm{Zn}_{0.97} \mathrm{Co}_{0.03} \mathrm{O}\right.$ and $\left.\mathrm{Zn}_{0.95} \mathrm{Co}_{0.05} \mathrm{O}\right)$, while the $\mathrm{O}_{\mathrm{i}}$ emission band completely disappeared in all the spectra for the Co-doped thin film. The increase in the intensity of the $V_{O}$ emission band for the Co-doped thin films, as will be presented below, corroborates the results obtained in XANES analyses, corresponding to the variations in white-line absorption peak intensity.

Fig. 7(a) shows the XANES spectra obtained for the $\mathrm{Zn}_{1-x^{-}}$ $\mathrm{Co}_{x} \mathrm{O}$ thin films at the Co K-edge and for the reference Co oxides: $\mathrm{CoO}$ (oxidation state +2 ), $\mathrm{Co}_{2} \mathrm{O}_{3}(+3)$ and metallic $\mathrm{Co}(0)$. We observed that the absorption edge for the thin films corresponds to the absorption edge of the reference oxide $\mathrm{CoO}$, in a way that we can concluded that the Co predominantly takes on the oxidation state +2 in our thin films. Once that the $\mathrm{Zn}$ has +2 oxidation state in the $\mathrm{ZnO}$ wurtzite matrix, it was expected that

Table 2 Integrated areas of the defect related emission bands obtained from Gaussian fit of the spectra of the $\mathrm{Zn}_{1-x} \mathrm{Co}_{x} \mathrm{O}$ thin films

\begin{tabular}{lllll}
\hline & & \multicolumn{3}{c}{$\begin{array}{l}\mathrm{Zn}_{\mathrm{i}} \rightarrow \\
\mathrm{V}_{\mathrm{Zn}},\end{array}$} \\
Sample & $\mathrm{V}_{\mathrm{O}}, 1.984 \mathrm{eV}$ & $\mathrm{O}_{\mathrm{i}}, 2.182 \mathrm{eV}$ & $2.449 \mathrm{eV}$ & $\mathrm{Zn}_{\mathrm{i}}, 2.895 \mathrm{eV}$ \\
\hline Undoped $\mathrm{ZnO}$ & $11.3(1)$ & $3.6(1)$ & $1.73(3)$ & - \\
$\mathrm{Zn}_{0.99} \mathrm{Co}_{0.01} \mathrm{O}$ & $7.28(2)$ & - & $5.40(2)$ & $1.06(1)$ \\
$\mathrm{Zn}_{0.97} \mathrm{Co}_{0.03} \mathrm{O}$ & $8.35(1)$ & - & $12.86(5)$ & $3.26(5)$ \\
$\mathrm{Zn}_{0.95} \mathrm{Co}_{0.05} \mathrm{O}$ & $32.0(1)$ & - & $40.7(2)$ & $15.1(2)$
\end{tabular}

Co would too occupy the same state, if it had been in a substitutional character to $\mathrm{Zn}$. Therefore, this result is another indication that $\mathrm{Co}^{2+}$ ions in our samples occupy the sites of the $\mathrm{Zn}^{2+}$ ions in the $\mathrm{ZnO}$ wurtzite structure. Furthermore, we observed that the white-line (maximum after absorption edge) decreases and shifts to lower energies with the increase in Co concentration, inset in Fig. 7(a). This behavior is directly associated with an increase in the empty states left by open bonds due to oxygen vacancies $\left(\mathrm{V}_{\mathrm{O}}\right) .{ }^{11}$ This result corroborates the data obtained from PL presented above, concerning the relative intensities of the emission bands associated with the $\mathrm{V}_{\mathrm{O}}$. The XANES is also very sensitive to the local geometry around the absorber atom and therefore, can be used as a signature to identify the Co site location in the analyzed structure. ${ }^{53,54}$ In Fig. 7(a), we observed the presence of peaks in the pre-edge region in the absorption spectra of the $\mathrm{Zn}_{1-x} \mathrm{Co}_{x} \mathrm{O}$ thin films. The pre-edge peak specifically originates from $\mathrm{s} \rightarrow \mathrm{d}$ transitions. In principle, the dipole selection rules do not allow this excitation. However, the observation of a pre-edge peak is associated with the existence of hybridization between the $\mathrm{p}$ and d states, which, in turn, is only possible if the site, where Co is located, does not have an inversion center of symmetry, as in a tetrahedral configuration. Therefore, the presence of the preedge peak in the obtained spectra lead us to state once more that in our thin films the $\mathrm{Co}^{2+}$ ions are located in tetrahedral sites, what would be expected considering that the $\mathrm{Co}^{2+}$ ions are replacing the $\mathrm{Zn}^{2+}$ ones in the $\mathrm{ZnO}$ wurtzite structure.

The shape of the absorption edge depends on the unfilled local density of states and the coordination symmetry of the absorbing element. Fig. 7(b) shows the extended XANES spectra obtained for the thin films at the $\mathrm{Zn}$ and Co K-edges. A very large correlation among the oscillations is observed, unlike other magnetic semiconductors where the transition metal atoms are in interstitial sites in the host matrix. ${ }^{55,56}$ Thus our results for the XANES spectra strongly indicate a substitutional incorporation of $\mathrm{Co}$ into the $\mathrm{ZnO}$ matrix. ${ }^{54}$

The short-range structural data provided by extended X-ray absorption fine structure (EXAFS) spectroscopy offer element specific insight, furnishing quantitative information about the numbers, positions, and identities of atoms surrounding the absorbing element, as well as structural disorder within the coordination spheres. The fitted $\mathrm{k}^{3}$-weighted Fourier transforms (FT) of the $\mathrm{Zn}_{1-x} \mathrm{Co}_{x} \mathrm{O}$ thin films are shown in Fig. 8(a), and the fitting and experimental EXAFS spectra of the backtransformations are shown in Fig. 8(b). The EXAFS data were obtained at Co K-edge for the studied thin films. The extraction and fitting of EXAFS spectra were performed using MultiPlatform Applications for X-ray absorption (MAX). Ab initio FEFF9 code was used to calculate the theoretical spectra. To obtain quantitative structural data concerning the first coordination shells, the neighborhood of Co atoms was modeled through the two main peaks corresponding to the two successive O spheres (between 1.5 and $3.0 \AA$ A) from FT-EXAFS. In all fits, we considered single and multi-scattering paths corresponding to the four successive atomic shells around Co substitutionally placed at $\mathrm{Zn}$ sites of the $\mathrm{ZnO}$ structure according to the hexagonal wurtzite with $\mathrm{P6}_{3} \mathrm{mc}$ space group. It is observed in Fig. 8(a) 

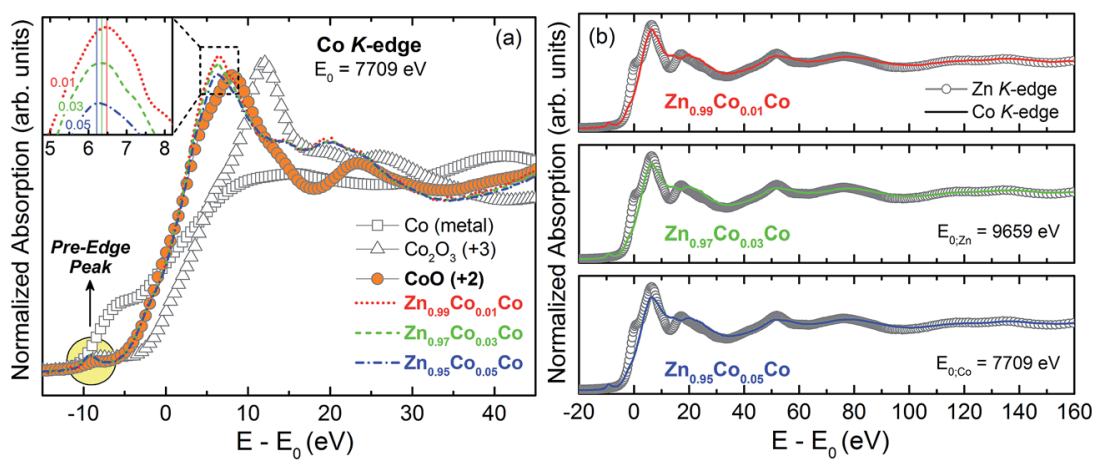

Fig. 7 (a) $\mathrm{Co} \mathrm{K}$-edge XANES spectra for the $\mathrm{Zn}_{1-x} \mathrm{Co}_{x} \mathrm{O}$ thin films. Metallic $\mathrm{Co}, \mathrm{CoO}$ (oxidation state +2$)$ and $\mathrm{Co}_{2} \mathrm{O}_{3}(+3)$ spectra are also shown for comparison. The inset highlights the variation of the intensity of the white-line as a function of Co concentration. (b) Comparison of the Co and Zn K-edge extended XANES spectra.
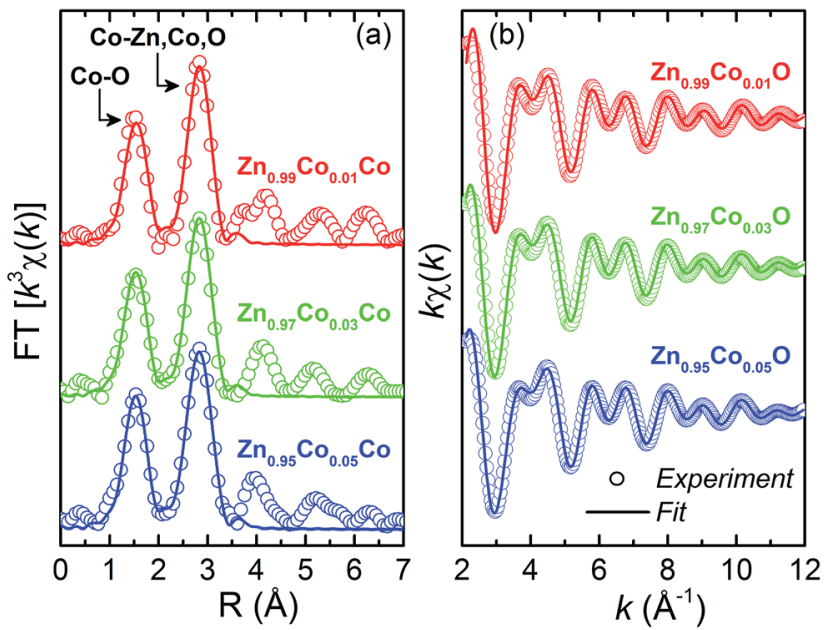

Fig. 8 (a) Fitted $k^{3}$-weighted Fourier transforms (FT) of the $\mathrm{Zn}_{1-x} \mathrm{Co}_{x} \mathrm{O}$ thin films and (b) fitted and experimental EXAFS spectra of the backtransformation. Open symbols are experimental data, and solid lines represent fittings using the parameters listed in Table 3 . The spectra are offset for clarity.

and (b) a good correlation between the experimental data and the obtained theoretical simulation, corroborating the previous results in favor of the Co incorporation into the $\mathrm{ZnO}$ matrix in a substitutional character to $\mathrm{Zn}$. The results obtained in the simulations, such as the values of the interatomic distances $(R)$, the coordination number $(N)$, the Debye-Waller values $\left(\sigma^{2}\right)$ and the quality factor $(\mathrm{QF})$ are presented in Table 3.

Analyzing the coordination number $(N)$, we observed a reduction in the number of $\mathrm{O}$ neighbors, indicating an increase in the oxygen vacancies in the doping process, corroborating the XANES and the PL analyses concerning the presence and the increase of the $\mathrm{V}_{\mathrm{O}}$ by increasing the Co content in the thin films. Likewise, there is an increase in the number of $\mathrm{Zn}$ neighbors, as we increase the Co-doping. This means that there is a relationship between the $\mathrm{V}_{\mathrm{Zn}}$ reduction and the addition of Co to the $\mathrm{ZnO}$ matrix. Also corroborating the $\mathrm{PL}$ analyses related to the low concentration of $\mathrm{V}_{\mathrm{Zn}}$ defects in the $\mathrm{Zn}_{1-x} \mathrm{Co}_{x} \mathrm{O}$ thin films.
Table 3 Co K-edge EXAFS simulation results. Interatomic distances $(R)$, the average coordination number $(N)$, Debye-Waller value $\left(\sigma^{2}\right)$ and quality factor (QF)

\begin{tabular}{llllll}
\hline Sample & Shell & $R(\AA)$ & $N$ & $\sigma^{2}\left(\AA^{2}\right)$ & QF \\
\hline $\mathrm{Zn}_{0.99} \mathrm{Co}_{0.01} \mathrm{O}$ & $\mathrm{Co}-\mathrm{O}$ & $1.98(1)$ & $4(1)$ & $0.008(2)$ & 3.51 \\
& $\mathrm{Co}-\mathrm{Zn}$ & $3.19(2)$ & $4(2)$ & $0.008(1)$ & \\
& $\mathrm{Co}-\mathrm{Zn}$ & $3.24(1)$ & $4(2)$ & $0.008(1)$ & \\
& $\mathrm{Co}-\mathrm{O}$ & $3.75(1)$ & $11(2)$ & $0.006(2)$ & \\
$\mathrm{Zn}_{0.97} \mathrm{Co}_{0.03} \mathrm{O}$ & $\mathrm{Co}-\mathrm{O}$ & $1.98(1)$ & $4.6(6)$ & $0.006(2)$ & 1.16 \\
& $\mathrm{Co}-\mathrm{Zn}$ & $3.19(1)$ & $6(1)$ & $0.009(1)$ & \\
& $\mathrm{Co}-\mathrm{Zn}$ & $3.24(1)$ & $6(1)$ & $0.009(1)$ & \\
& $\mathrm{Co}-\mathrm{O}$ & $3.76(1)$ & $9(2)$ & $0.006(2)$ & \\
$\mathrm{Zn}_{0.95} \mathrm{Co}_{0.05} \mathrm{O}$ & $\mathrm{Co}-\mathrm{O}$ & $1.97(1)$ & $4.2(6)$ & $0.004(2)$ & 1.11 \\
& $\mathrm{Co}-\mathrm{Zn}$ & $3.18(8)$ & $6(1)$ & $0.010(1)$ & \\
& $\mathrm{Co}-\mathrm{Zn}$ & $3.25(2)$ & $7(1)$ & $0.010(1)$ & \\
& $\mathrm{Co}-\mathrm{O}$ & $3.71(1)$ & $7(2)$ & $0.004(2)$ & \\
& & & & & \\
& & & & & \\
& & & &
\end{tabular}

In the context of the magnetic properties of the dilute magnetic oxides (DMOs) the most accepted theoretical model is the spin-split impurity band model, also called bound magnetic polaron (BMP) theory. ${ }^{27}$ The BMP theory states that the hybridization between the magnetic dopant and the defect levels leads to a delocalization of the carriers at the Fermi level over the magnetic dopants. In especial for the Co-doped $\mathrm{ZnO}$, the $\mathrm{Co}^{2+}$ ions can hybridize effectively with shallow-donor impurity bands in $\mathrm{ZnO}$ because the states related to the complex $\mathrm{Co}^{+}\left(\mathrm{Co}^{2+}+\mathrm{e}_{\mathrm{donor}}{ }^{-}\right)$are also of shallow-donor character. ${ }^{45}$ However, the nature of the specific donor point defect necessary to form the BMP is a matter of debate. On the literature one can find several experimental reports arguing, under the scope of the BMP theory, that oxygen vacancies $\left(\mathrm{V}_{\mathrm{O}}\right)^{44,57}$ are the responsible one of the often observed RTFM, besides, zinc interstitials $\left(\mathrm{Zn}_{\mathrm{i}}\right)$ has been cited very often. ${ }^{22,58-60}$ However, the $\mathrm{V}_{\mathrm{O}}$ state in the wurtzite $\mathrm{ZnO}$ is deep-donor state, ${ }^{51,61}$ and, although deeper-donors states can hybridize to magnetic dopants, their smaller Bohr radii would require relatively higher dopant and defect concentrations to achieve a necessary spatial overlapping, and at such short-range antiferromagnetic superexchange interactions would be observed, instead of the desired ferromagnetic coupling. ${ }^{48}$ Therefore, the most promising 
shallow-donor defect in the $\mathrm{ZnO}$ structure is the zinc interstitials $\left(\mathrm{Zn}_{\mathrm{i}}\right) .{ }^{\mathbf{5 1 , 6 1}}$ As we have directly addressed in the previous analyses, due the presence of both defects, $\mathrm{V}_{\mathrm{O}}$ and $\mathrm{Zn}_{\mathrm{i}}$, in our thin films, in spite of the controversy and in the scope of the BMP theory, we can state that the studied samples would be candidates to present an intrinsic RTFM.

\section{Conclusions}

In summary, we shown that the polymeric precursor method is, besides its low-cost, a high-effective route of synthesis of nanostructured Co-doped $\mathrm{ZnO}\left(\mathrm{Zn}_{1-x} \mathrm{Co}_{x} \mathrm{O}\right)$ thin films up to $x=0.05$. From the structural point of view, the synthesis of nanostructured dilute magnetic oxides was successful. We performed a broad structural and optical characterization. The results confirm that $\mathrm{Co}^{2+}$ ions substitute for $\mathrm{Zn}^{2+}$ ions in the wurtzite ZnO matrix. There is no indication of Co-rich nanoclusters or segregated secondary phases in the samples. It was further observed that the major structural defects in the films are $\mathrm{V}_{\mathrm{O}}$ and $\mathrm{Zn}_{\mathrm{i}}$, and that the relative densities of these defects increase with the increase of the Co concentration in the thin films. These results promote the studied thin films to candidates to present the desired ferromagnetic order at room temperature.

\section{Acknowledgements}

Support from agencies FAPEMIG (APQ-02486-14; APQ-0027314), CNPq (448723/2014-0; 308162/2015-3, 470069/2013-9), FAPESP (2013/07909-4), FINEP (ref. 134/08) and CAPES (PNPD2011) are gratefully acknowledged. We also thank CNPq (MIBB and ACD) and CAPES (NCM, AOZ) for research fellowships. The authors also acknowledge Prof. Dr F. Iikawa and Profa. Dra. M. J. S. Brasil of the Universidade de Campinas (UNICAMP) for the PL measurements.

\section{References}

1 I. Zutic, J. Fabian and S. Das Sarma, Spintronics: Fundamentals and Applications, Rev. Mod. Phys., 2004, 76(2), 323-410.

2 A. Hirohata and K. Takanashi, Future perspectives for spintronic devices, J. Phys. D: Appl. Phys., 2014, 47(19), 193001.

3 U. Hartmann, Magnetic Multilayers and Giant Magnetoresistance, Springer, Berlin, 2000.

4 J. S. Moodera and R. H. Meservey, Spin-polarized tunnelling magnetoelectronics, Elsevier, Amsterdam, 2004.

5 H. B. de Carvalho, et al., Transport and magnetotransport transition of thin Co films grown on Si, Phys. Status Solidi A, 2004, 201(10), 2361-2365.

$6 \mathrm{M}$. Knobel, et al., Magnetic and magnetotransport properties of Co thin films on Si, Phys. Status Solidi A, 2001, 187(1), 177-188.

$7 \mathrm{H}$. Ohno, et al., Electric-field control of ferromagnetism, Nature, 2000, 408(6815), 944-946.

8 Y. Fukuma, et al., Carrier-induced ferromagnetism in $\mathrm{Ge}_{0.92} \mathrm{Mn}_{0.08}$ Te epilayers with a Curie temperature up to 190 K, Appl. Phys. Lett., 2008, 93(25), 252502.
9 M. Wang, et al., Achieving high Curie temperature in (Ga, Mn)As, Appl. Phys. Lett., 2008, 93(13), 132103.

10 T. Dietl, et al., Zener model description of ferromagnetism in zinc-blende magnetic semiconductors, Science, 2000, 287(5455), 1019-1022.

11 T. E. de Souza, et al., Structural and Magnetic Properties of Dilute Magnetic Oxide Based on Nanostructured Co-Doped Anatase $\mathrm{TiO}_{2}\left(\mathrm{Ti}_{1-x} \mathrm{Co}_{x} \mathrm{O}_{2}\right.$-delta), J. Phys. Chem. C, 2013, 117(25), 13252-13260.

12 M. I. B. Bernardi, et al., The role of oxygen vacancies and their location in the magnetic properties of $\mathrm{Ce}_{1-x} \mathrm{Cu}_{x} \mathrm{O}_{2}$ delta nanorods, Phys. Chem. Chem. Phys., 2015, 17(5), 3072-3080.

13 A. Punnoose, et al., Room-temperature ferromagnetism in chemically synthesized $\mathrm{Sn}_{1-x} \mathrm{Co}_{x} \mathrm{O}_{2}$ powders, Appl. Phys. Lett., 2004, 85(9), 1559-1561.

14 M. Venkatesan, et al., Anisotropic ferromagnetism in substituted zinc oxide, Phys. Rev. Lett., 2004, 93(17), 177206.

15 Y. Belghazi, et al., Extrinsic origin of ferromagnetism in $\mathrm{ZnO}$ and $\mathrm{Zn}_{0.9} \mathrm{Co}_{0.1} \mathrm{O}$ magnetic semiconductor films prepared by sol-gel technique, Appl. Phys. Lett., 2006, 89(12), 122504.

16 J. M. D. Coey, Dilute magnetic oxides, Curr. Opin. Solid State Mater. Sci., 2006, 10(2), 83-92.

17 D. C. Kundaliya, et al., On the origin of high-temperature ferromagnetism in the low-temperature-processed $\mathrm{Mn}-\mathrm{Zn}$ O system, Nat. Mater., 2004, 3(10), 709-714.

$18 \mathrm{M}$. Tay, et al., Ferromagnetism in inhomogeneous $\mathrm{Zn}_{1-x} \mathrm{Co}_{x} \mathrm{O}$ thin films, J. Appl. Phys., 2006, 100(6), 063910.

19 H. B. de Carvalho, et al., Absence of ferromagnetic order in high quality bulk Co-doped ZnO samples, J. Appl. Phys., 2010, 108(3), 033914.

20 S. Kolesnik, B. Dabrowski and J. Mais, Structural and magnetic properties of transition metal substituted ZnO, J. Appl. Phys., 2004, 95(5), 2582-2586.

21 E. Z. Liu, Y. He and J. Z. Jiang, Ferromagnetism induced by defect complex in Co-doped ZnO, Appl. Phys. Lett., 2008, 93(13), 132506.

22 N. Khare, et al., Defect-induced ferromagnetism in co-doped ZnO, Adv. Mater., 2006, 18(11), 1449-1452.

23 M. P. F. de Godoy, et al., Evidence of defect-mediated magnetic coupling on hydrogenated Co-doped ZnO, J. Alloys Compd., 2013, 555, 315-319.

24 V. M. de Almeida, et al., Room temperature ferromagnetism promoted by defects at zinc sites in Mn-doped ZnO, J. Alloys Compd., 2016, 655, 406-414.

25 N. K. Mamani, et al., On the nature of the room temperature ferromagnetism in nanoparticulate Co-doped $\mathrm{ZnO}$ thin films prepared by EB-PVD, 2017, pp. 2682-2688.

26 A. Walsh, J. L. F. Da Silva and S.-H. Wei, Theoretical description of carrier mediated magnetism in cobalt doped ZnO, Phys. Rev. Lett., 2008, 100(25), 256401.

27 J. M. D. Coey, M. Venkatesan and C. B. Fitzgerald, Donor impurity band exchange in dilute ferromagnetic oxides, Nat. Mater., 2005, 4(2), 173-179.

28 M. Venkatesan, C. B. Fitzgerald and J. M. D. Coey, Unexpected magnetism in a dielectric oxide, Nature, 2004, 430(7000), 630. 
29 J. M. D. Coey, et al., Charge-transfer ferromagnetism in oxide nanoparticles, J. Phys. D: Appl. Phys., 2008, 41(13), 134012.

30 M. Law, et al., Nanowire dye-sensitized solar cells, Nat. Mater., 2005, 4(6), 455-459.

31 M. Bender, et al., Production and characterization of zinc oxide thin films for room temperature ozone sensing, Thin Solid Films, 2002, 418(1), 45-50.

32 J. H. Lee, K. H. Ko and B. O. Park, Electrical and optical properties of $\mathrm{ZnO}$ transparent conducting films by the solgel method, J. Cryst. Growth, 2003, 247(1-2), 119-125.

33 R. Ullah and J. Dutta, Photocatalytic degradation of organic dyes with manganese-doped $\mathrm{ZnO}$ nanoparticles, J. Hazard. Mater., 2008, 156(1-3), 194-200.

34 M. Pechini, Method of Preparing Lead and Alkaline Earth Titanates and Niobates and Coating Method Using the Same to Form a Capacitor, United States of America, 1967.

35 M. Alain, et al., MAX: Multiplatform Applications for XAFS, in 14th International Conference on $X$-Ray Absorption Fine Structure (XAFS14), Camerino, ITALY, 2009.

36 A. L. Ankudinov, et al., Real-space multiple-scattering calculation and interpretation of X-ray-absorption nearedge structure, Phys. Rev. B: Condens. Matter Mater. Phys., 1998, 58, 7565.

37 E. Limpert, W. Stahel and M. Abbt, Log-normal distributions across the sciences: keys and clues, Bioscience, 2001, 51(5), 341-352.

38 H. A. Weakliem, Optical spectra of $\mathrm{Ni}^{2+}, \mathrm{Co}^{2+}$, and $\mathrm{Cu}^{2+}$ in tetrahedral sites in crystals, J. Chem. Phys., 1962, 36(8), 2117-2140.

39 J. Ferguson, D. Wood and L. G. Vanuiter, Crystal-field spectra of D3,7 ions.v. tetrahedral $\mathrm{CO}^{2+}$ in $\mathrm{ZnAl}_{2} \mathrm{O}_{4}$ spinel, J. Chem. Phys., 1969, 51(7), 2904-2910.

40 P. Koidl, Optical-absorption of $\mathrm{Co}^{2+}$ in $\mathrm{ZnO}$, Phys. Rev. B: Solid State, 1977, 15(5), 2493-2499.

$41 \mathrm{~J}$. TAUC, Optical properties and electronic structure of amorphous Ge and Si, Mater. Res. Bull., 1968, 3(1), 37-46.

42 R. Shannon, Revised effective ionic radii and systematic studies of interatomic distances in halides and chalcogenides, Acta Crystallogr., Sect. A: Cryst. Phys., Diffr., Theor. Gen. Crystallogr., 1976, 32(5), 751-767.

43 F. L. Martinez, et al., Optical properties and structure of $\mathrm{HfO}_{2}$ thin films grown by high pressure reactive sputtering, J. Phys. D: Appl. Phys., 2007, 40(17), 5256-5265.

$44 \mathrm{M}$. Ivill, et al., Structure and magnetism of cobalt-doped $\mathrm{ZnO}$ thin films, New J. Phys., 2008, 10, 10.

45 K. R. Kittilstved, W. K. Liu and D. R. Gamelin, Electronic structure origins of polarity-dependent high-T-C ferromagnetismin oxide-diluted magnetic semiconductors, Nat. Mater., 2006, 5(4), 291-297.

46 T. T. Loan, N. N. Long and L. H. Ha, Photoluminescence properties of Co-doped $\mathrm{ZnO}$ nanorods synthesized by hydrothermal method, J. Phys. D: Appl. Phys., 2009, 42(6), 065412.

47 J. M. Calleja and M. Cardona, Resonant Raman-Scattering in ZnO, Phys. Rev. B: Solid State, 1977, 16(8), 3753-3761.

48 A. Mesquita, et al., Dynamics of the incorporation of Co into the wurtzite $\mathrm{ZnO}$ matrix and its magnetic properties, J. Alloys Compd., 2015, 637, 407-417.

49 R. Cusco, et al., Temperature dependence of Raman scattering in ZnO, Phys. Rev. B: Condens. Matter Mater. Phys., 2007, 75(16), 165202.

50 B. Lin, Z. Fu and Y. Jia, Green luminescent center in undoped zinc oxide films deposited on silicon substrates, Appl. Phys. Lett., 2001, 79(7), 943-945.

$51 \mathrm{P} . \mathrm{Xu}$, et al., The electronic structure and spectral properties of $\mathrm{ZnO}$ and its defects, Nucl. Instrum. Methods Phys. Res., Sect. $B, 2003,199,286-290$.

52 C. X. Xu, et al., Photoluminescent properties of copperdoped zinc oxide nanowires, Nanotechnology, 2004, 15(7), 856-861.

53 J. Pellicer-Porres, et al., Tetrahedral versus octahedral Mn site coordination in wurtzite and rocksalt $\mathrm{Zn}_{1-x} \mathrm{Mn}_{x} \mathrm{O}$ investigated by means of XAS experiments under high pressure, Superlattices Microstruct., 2007, 42(1-6), 251-254.

54 G. Martinez-Criado, et al., X-ray absorption in GaGdN: a study of local structure, Appl. Phys. Lett., 2008, 93(2), 021916.

55 W. T. Geng and K. S. Kim, Structural, electronic, and magnetic properties of a ferromagnetic semiconductor: Codoped $\mathrm{TiO}_{2}$ rutile, Phys. Rev. B: Condens. Matter Mater. Phys., 2003, 68(12), 125203.

56 A. Continenza, G. Profeta and S. Picozzi, Transition metal impurities in Ge: chemical trends and codoping studied by electronic structure calculations, Phys. Rev. B: Condens. Matter Mater. Phys., 2006, 73(3), 035212.

57 S. Ramachandran, J. Narayan and J. T. Prater, Effect of oxygen annealing on $\mathrm{Mn}$ doped $\mathrm{ZnO}$ diluted magnetic semiconductors, Appl. Phys. Lett., 2006, 88(24), 242503.

58 K. R. Kittilstved, et al., Direct kinetic correlation of carriers and ferromagnetism in $\mathrm{Co}^{2+}: \mathrm{ZnO}$, Phys. Rev. Lett., 2006, 97(3), 037203.

59 D. A. Schwartz and D. R. Gamelin, Reversible $300 \mathrm{~K}$ ferromagnetic ordering in a diluted magnetic semiconductor, Adv. Mater., 2004, 16(23-24), 2115-2119.

60 M. H. F. Sluiter, et al., First principles based design and experimental evidence for a $\mathrm{ZnO}$-based ferromagnet at room temperature, Phys. Rev. Lett., 2005, 94(18), 187204.

61 A. Janotti and C. G. Van de Walle, Native point defects in ZnO, Phys. Rev. B: Condens. Matter Mater. Phys., 2007, 76(16), 165202. 